\title{
Experimentar el paso de Dios: diálogo entre exégesis, teología y tradición en Ex 33,12-23*
}

\author{
Jorge Yecid Triana Rodríguez ${ }^{a}$ \\ Universidad de la Salle y Uniminuto, Colombia \\ http://orcid.org/0000-0001-8876-5435 \\ Ivonne Adriana Méndez Paniagua \\ Uniminuto, Colombia \\ http://orcid.org/0000-0001-9331-9093
}

RECIBIDO: 30-08-19. APROBADO: 09-12-19

Resumen: En este trabajo se indagan los resultados obtenidos de la exégesis diacrónica aplicados en la perícopa de Éx 33,12-33, y se resalta el aporte teológico de la crítica de las redacciones en el contexto de la unidad literaria del Pentateuco; esto, como propuesta metodológica que favorece la comprensión de la perícopa desde la mirada holística de las fuentes antiguas y otros materiales preexílicos diferentes que componen este bloque literario. Estos resultados son considerados además como la base o el fundamento para obtener las claves teológicas de la perícopa desde las categorías conceptuales de la Ley y el culto, en los que se tienen en cuenta las dos unidades redaccionales de la misma, ubicadas así: la primera, del v. 12 al v. 17; y la segunda, del v. 18 al v. 23. Es así como las teologías emergentes del culto y la Ley son clave de lectura en el marco teológico de la alianza que les da los rasgos y características propias en el relato bíblico.

A su vez, los aportes que las tradiciones interpretativas de origen halakitas y haggaditas, propias del midrás rabínico y sus middot, son referentes teológicos que permiten nuevas categorías de estudio, análisis y actualización de los contenidos bíblicos, presentes en la perícopa de estudio y en toda la obra del Pentateuco. Este proceso de exégesis, teología e interpretación bíblica se propone como alternativa investigativa y pedagógica para un mayor y mejor acercamiento al estudio integral y la comprensión más amplia de los cinco primeros libros del canon bíblico, el cual proporciona e incorpora herramientas de actualización del mensaje revelado, tanto en las perspectivas éticas, jurídicas y litúrgicas propias de la experiencia de fe judía como de la fe cristiana.

Palabras Clave: Éxodo; exégesis; teología; diálogo; tradición; interpretación; Pentateuco.

*Artículo de investigación.

aAutor de correspondencia. Correo electrónico: jytriana@unisalle.edu.co 


\section{Experiencing God's Passage: A Dialogue between Exegesis, \\ Theology and Tradition in Exodus 33,12-23}

AвSTRACT: This work investigates the results obtained from the diachronic exegesis applied in the pericope of Ex 33,12- 23, and highlights the theological contribution of the redactional criticism in the context of the literary unity of the Pentateuch; this, as a methodological proposal that favors the pericope understanding from the holistic view of ancient sources and other different pre-exilic materials that make up this literary block. These results are also considered the basis or foundation to obtain the theological keys of the pericope from the conceptual categories of Law and worship, which consider the two editorial units of the same, located as follows: first, v. 12 to v. 17 ; second, v. 18 to v. 23. This is how the theologies emerging from worship and the Law are key to reading in the theological framework of the covenant. In this way, their analysis and interpretation contribute to the understanding of the narrative and thematic core of the Pentateuch. In turn, the contributions that the interpretative traditions of Halakite and Haggadite origin, typical of the rabbinic midras and its middot, are theological references that allow new categories of study, analysis and updating of the biblical contents, present in the study pericope and throughout the Pentateuch. This process of exegesis, theology and biblical interpretation is proposed as an investigative and pedagogical alternative for a greater and better approach to integral study, and the comprehensive study and broader understanding of the first five books of the biblical canon, which provides and incorporates tools for updating the revealed message, both in the ethical, legal, and liturgical perspectives of the Jewish faith and the Christian faith experience.

KeY Words: Exodus; Exegesis; Theology; Dialogue; Tradition; Interpretation; Pentateuch.

\section{Cómo CITAR:}

Triana Rodríguez, Jorge Y., e Ivonne A. Méndez Paniagua. "Experimentar el paso de Dios: diálogo entre exégesis, teología y tradición en Éx 33,12-23”. Theologica Xaveriana (2021): 1-18. https://doi.org/10.11144/javeriana.tx71.epddett

\section{ReCONOCIMIENTO}

Este artículo de investigación es resultado de la tesis doctoral en Teología de Jorge Yecid Triana Rodríguez, que lleva el mismo título y fue realizada en la Universidad Pontificia Bolivariana, de 2015 a 2017. 


\section{Introducción}

La presente investigación se apoya en dos motivaciones que giran en torno de la experiencia de estudios y docencia en Sagrada Escritura: en primer lugar comprender los procesos académicos de la exégesis bíblica, donde se plantea la composición del Pentateuco en sus aspectos literarios, contextuales y teológicos; en segundo lugar apropiar un modelo pedagógico para socializar dicha comprensión, asumiendo los resultados de la exégesis, la teología y la interpretación bíblica.

Tales búsquedas desembocan en la constatación de un amplio desarrollo de los estudios del Pentateuco, cada vez más diversos, confrontados y novedosos, en la evidencia de planteamientos sobre la posibilidad de desarrollar una teología bíblica del Antiguo Testamento en la que se esbozan teologías emergentes, y en la presentación del midrás, entendido como técnica rabínica y como teología judía interpretativa.

\section{Planteamiento metodológico}

La perícopa de estudio es Ex 33,12-23, sobre la cual se articulan los resultados de la exégesis redaccional, la teología bíblica y el midrás, según una metodología propia para cada momento analítico: la teología contenida en las diferentes redacciones que intervinieron sobre el texto, los procedimientos histórico-descriptivos para señalar las teologías de la Ley y el culto contenidas en la perícopa y transversales al Pentatueco, y la aplicación de algunas middot al desarrollo de la misma como aporte teológicointerpretativo de la literatura rabínica.

Los alcances del estudio abarcan el Pentateuco, aunque se abre a la comparación con textos paralelos de los otros dos bloques literarios de la TaNaK, al tomar como referencia literaria la Biblia Hebraica Stutgartensia ${ }^{1}$, aunque las variantes de la LXX permiten ver una lectura teológica propia que ubica esta versión en el campo interpretativo más que en el de la traducción. De igual manera, se abre a la posibilidad de una lectura intertextual donde se articulen los dos testamentos, la cual permite desarrollar una propuesta de teología canónica contenida en la perícopa y en otras de los evangelios, como en el caso de Jn 14,1-11, que ameritaría desarrollos ulteriores.

\section{Resultados a partir de la indagación y la metodología aplicada}

En cuanto a los resultados sobre la composición del Pentateuco se acude a proclamar la locura de la hipótesis documentaria, en términos de Cortese², o a una gran confusión,

\footnotetext{
${ }^{1}$ Véase a Elliger y Rudolph (eds.), Biblia Hebraica Stuttgartensia.

${ }^{2}$ Cortese, "Pentateuco: la strada vecchia e la nuova", 72.
} 
como plantean $\mathrm{Ska}^{3} \mathrm{y}$ otros autores que proponen diversas soluciones, o al menos plantean vías alternas ${ }^{4}$ hasta la negación total de la existencia de fuentes 5 . El punto actual de verificación está en el reconocimiento de la redacción sacerdotal y el material de este tipo contenido en el conjunto de la obra, en su relación con el material denominado presacerdotal, en este caso de origen Jeovista, JE, y los aportes pos-sacerdotales $\mathrm{P}^{\mathrm{s}}$ al conjunto redaccional.

Las dataciones de las fuentes, en las que se otorgaba mayor antigüedad al J, se han replanteado hasta presentarlo como una corrección $\mathrm{D}^{6}$, haciendo menos énfasis en la independencia literaria de las fuentes y por tanto teológica. Los barridos exhaustivos a modo de cernidora sobre los pasajes del Pentateuco mostraron la imposibilidad de separarlos y apuntaron a la combinación de fuentes antiguas, JE, o a postular el documento Elohista, E, como la base del Sacerdotal, P ( $\left.{ }^{\mathrm{g}}\right)$.

En suma, solo se identificará el papel redaccional Deuteronomista, D, y P, aludiendo al reconocimiento de diferentes materiales preexílicos como apoyo a sus composiciones y las nuevas vertientes de esta hipótesis o la de los fragmentos, como propuso Rendtorff en su investigación?

Con los valiosos aportes de von $\mathrm{Rad}^{8}$ sobre las tradiciones literarias y sus postulados de los credos históricos, su sucesor Rendtorff, ya citado, acudió a desempolvar la hipótesis de los fragmentos, dando sepultura a la hipótesis documentaria. Aun así, y con el esfuerzo de algunos jinetes defensores, se han postulado nuevas y variadas posturas que cambian el orden y, por tanto, las dataciones de las fuentes queriendo mantener la hipótesis en pie. De igual manera se vinculan nuevos ingredientes de tipo contextual.

La apuesta, por tanto, al desistir de extensas y bizantinas elaboraciones que fragmentan cada vez más los conjuntos literarios, radica en buscar nuevas y sólidas explicaciones a las composiciones literarias, en este caso del Pentateuco, cada vez más de corte sincrónico (lectura poética, retórica, narrativa, etc.) y teológico. De ahí la

${ }^{3}$ Ska, Introduction à la lecture du Pentateuque. Clés pour l'interprétation des cinq premiers livres de la Bibla, 181.

${ }^{4}$ Buss, "Bundestheologie im Alten Testament by Lothar Perlitt" [recension], 210-212; Bauks y Nihan, Manuel d'exégèse de L'Ancien Testament; Römer, Macchi y Nihan (eds.), Introduction à L'Ancien Testament.

${ }^{5}$ Rendtorff, "Das überlieferungsgeschichtliche. Problem des Pentateuch"; Van Seters, "Abraham in History and Tradition", 58-77; Schmid, Der Sogenannte Jawist. Beobachtungen und Fragen zur Pentateuchforschung, Rose, Deuteronomist und Jawist. Untersuchungen zu den Berührungspunkten beider Literaturwerke; Blum, Studien zur Komposition ds Pentateuch, 256-257.

${ }^{6}$ García López, La Torá. Escritos sobre el Pentateuco, 57.

7 Ver a Rendtorff, "Das überlieferungsgeschichtliche. Problem des Pentateuch".

${ }^{8}$ Citado por Emerton, Studies in the Pentateuch, 112. 
validez de proponer la articulación entre la exégesis histórico-crítica y sus resultados de validación histórica de los sustratos literarios, y la teología bíblica, que se muestra en los aportes histórico-redaccionales y la interpretación bíblica como el esfuerzo de actualización de dichas perspectivas teológicas.

\section{Crítica redaccional de Ex 33,12-23}

Entre los estudios histórico-críticos del Antiguo Testamento se ha venido enfatizando el carácter redaccional o compuesto de los bloques literarios, en este caso del Pentateuco. Los postulados de diferentes autores como Bauks y Nihan, ${ }^{9}$ Vermeylen ${ }^{10}$, $\mathrm{Ska}^{11}$ o Römer ${ }^{12}$ resaltan el papel de los redactores como el de verdaderos teólogos y no meros compiladores. Desde esta perspectiva se trata de identificar la prehistoria literaria de la perícopa en estudio y las revisiones sucesivas ${ }^{13}$ en relación con su contexto inmediato en el episodio del becerro de oro (Ex 32-34) y el más amplio dentro de la perícopa del Sinaí (Ex 19-40). Estos contextos son los que determinan la función redaccional y, por ende, teológica de la perícopa, así como su aporte al conjunto de la obra del Pentateuco.

En relación con el contexto de la perícopa del Sinaí, delimitada desde Ex 19,1

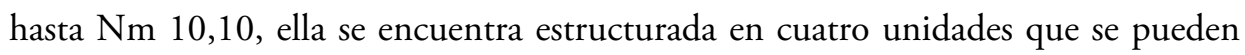
considerar paralelas y con funciones propias al interior del conjunto; a su vez, el estudio diacrónico ha determinado la proveniencia de diferentes fuentes que confluyen en la estructura final.

De esta manera, la unidad A $(19,1-24,18)$, donde se presenta el marco de la perícopa como teofanía en la que Yahveh promulga sus leyes directamente o a través de Moisés, se desenvuelve de manera poco coherente entre la montańa y la llanura, con el papel de los ancianos, Josué, Moisés y Yahveh; se aseguran leyes contenidas en el Decálogo y el denominado Código de la Alianza, se anuncia la guía de un mensajero delante del pueblo, y se prepara a Moisés para recibir las "tablas de piedra".

Las tradiciones subyacentes a esta sección son J y E, con retoques P que le dan el carácter teofánico en la introducción y la conclusión.

\footnotetext{
9 Ver a Bauks y Nihan C, Manuel d'exégèse de l'Ancien Testament.

${ }^{10}$ Ver a Vermeylen, El Dios de la promesa y el Dios de la alianza.

${ }^{11}$ Ver a Ska, El Pentateuco: un filón inagotable. Problemas de composición y de interpretación. Aspectos literarios y teológicos.

${ }^{12}$ Ver a Römer, La llamada historia deuteronomista. Una introducción sociológica, histórica y literaria.

${ }^{13}$ Bauks y Nihan, Manuel d'exégèse de L'Ancien Testament, 138.
} 
La unidad B $(25,1-31,18)$ evidencia un desarrollo claramente sacerdotal, referido a las órdenes de la construcción del santuario, con elementos tradicionales como el arca y la tienda, y otros más evolucionados del culto israelita.

La unidad C (32,1-34,35), del becerro de oro, en perspectiva paralela puede verse como la continuación de A y a la vez opuesta a esta unidad; también ha sido considerada la tipificación del pecado original de Israel. El escenario inicial se traslada a la llanura donde el pueblo reclama por la ausencia de Moisés y pide a Aarón una representación de Yahveh, quien acede a fabricar un becerro y hacer fiesta en su honor; por otra parte, en la montaña, donde está Moisés, Yahveh mismo le dice que baje; de inmediato, Moisés clama por el pueblo en la montaña; al bajar, tiene en sus manos las tablas del testimonio, nombre diferente a tablas de piedra, las destruye y reduce a polvo que esparce en agua y la hace beber al pueblo que los levitas le ayudan a purificar; Moisés recibe la orden de partir, y de nuevo se le confirma que un mensajero lo guiará. La tienda del encuentro es desplazada fuera del centro del campamento como signo del distanciamiento entre Yahveh y el pueblo.

De nuevo Moisés intercede en un diálogo de confidencialidad, como se refleja en las dos peticiones centrales de la perícopa en estudio: conocer sus caminos, ver su rostro (Ex 33,13.18). Se resuelve con la orden de subir de nuevo a la montańa con unas nuevas tablas de piedra; se da una nueva teofanía con términos de bondad y misericordia, en la que Moisés recibe nuevas normas de tipo cultual y desciende con el rostro radiante.

La unidad D $(35,1-40,38)$ indica la continuidad de B en cuanto ejecuta las órdenes de construcción del santuario. La perícopa cierra con la posesión de la tienda por parte de Yahveh, significado por la nube y el fuego. La unidad C contiene material E con posible Yavista, J, pero ante todo corresponde a la redacción D, responsable de suscitar la reflexión sobre el pecado de Jeroboam y los dos becerros de oro erigidos en el reino del Norte para marcar la división de los reinos y conducir al pueblo a la apostasía y desviación de los mandamientos. En el conjunto final se señala una tarea redaccional $\mathrm{P}^{\mathrm{s} .}$

A partir de los aspectos literarios y redaccionales se han distinguido tres partes que indican tres claves esenciales de lectura: alianza, ruptura de la alianza y su correspondiente renovación, a las que se añaden las órdenes para la construcción del santuario y su ejecución.

En el contexto más amplio de la perícopa del Sinaí, incluido el libro del Levítico

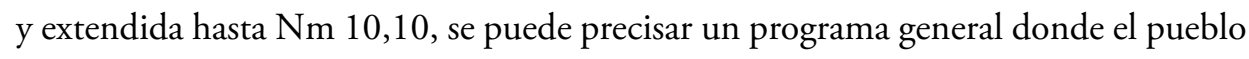


se consagra como propiedad de Yahveh, reino sacerdotal y nación santa ${ }^{14}$. También, la promulgación del Decálogo, las tablas del testimonio, la tienda del encuentro, el santuario, se presentan como nuevas relaciones entre Yahveh y su pueblo. En el becerro de oro se destaca como tema central la presencia de Yahveh como Dios de misericordia, con la alianza renovada. Además, es significativo el rol que desempeña Moisés, quien se destaca como legislador y mediador, siempre intercediendo por el pueblo para salvaguardar la alianza con Yahveh, si se toma la última redacción: “...el autor sacerdotal está sugiriendo que el contenido de la revelación del Sinaí es el culto sacrificial...” 15

A nivel teológico, las redacciones han resaltado los motivos del pecado de Israel, la actitud de los levitas y la purificación, la preparación y ejecución de la estructura cultual, las tablas y la tienda como mediaciones, la necesidad de representar a Yahveh, quien se proclama invisible a los ojos del hombre, la presencia de la nube que envuelve su gloria y la mediación de Moisés.

En Ex 33,12-23, Moisés toma la iniciativa en el diálogo, plantea interrogantes, hace memoria de afirmaciones pasadas, y provoca una reacción favorable en su interlocutor, con quien mantiene un diálogo de confianza y cercanía, demostrando el máximo de confidencialidad y explotándolo en su favor a partir de las declaraciones divinas "te conozco por nombre" y "has hallado mi favor".

Moisés se define también en el aspecto cultual hacia Yahveh, como en la invitación a mantenerse sobre la roca, que expresa un sentido típicamente sacerdotal ${ }^{16}$. Ex 33,21.22b puede estar literariamente próxima al relato deuteronomista del peregrinaje de Elías al Horeb (1R 19,9-10.15-17), que a su vez podría depender de Ex 33-34 y corresponder a la tercera redacción deuteronomista, con elementos tales como los siguientes:

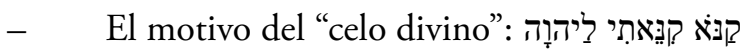

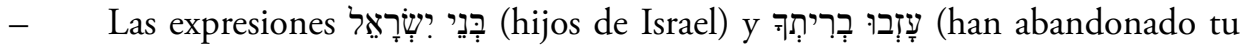
alianza)

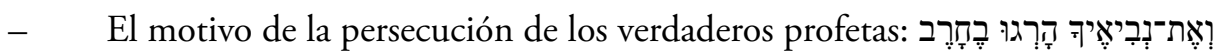

- La presentación de Elías como el campeón de Yahveh ante Jezabel, representante de Baal

\footnotetext{
${ }^{14}$ Ska, Introduction à la lecture du Pentateuque. Clés pour l'interprétation des cinq premiers livres de la Bible, 55.

${ }^{15}$ García López, La Torá. Escritos sobre el Pentateuco, 28.

${ }^{16}$ Vermeylen, “L'affaire du veau d'or (Ex 32-34) Une clé pour la 'question deuteronomiste??, 19.
} 
Además de tales características literarias, otro aporte de este paralelo consiste en indicar el lugar donde se desarrollaron los hechos del diálogo con Yahveh, tanto de Moisés como de Elías. Este lugar se deduce a partir de Ex 32,30-35, texto en el que Moisés dice al pueblo: "Ahora subiré a Yahveh; acaso pueda obtener el perdón para vuestro pecado" (v. 30cd). El diálogo se realiza en el monte Sinaí (Ex 19,6-25; 24,12; 31,18a), el cual en la tradición elohista recibe el nombre de Horeb (Ex 3,1; 17,6; 33,6), lugar de revelación y de naturaleza simbólica ${ }^{17}$. El nombre Horeb recorre sobre todo el Deuteronomio $(4,15 ; 5,2 ; 9,8 ; 18,16 ; 28,69)$, y se aprecia en los añadidos de la escuela deuteronomista (Ex 3,1; 33,6; 1 R 19,8).

Las palabras que expresan la idea de este lugar en el texto se encuentran en la

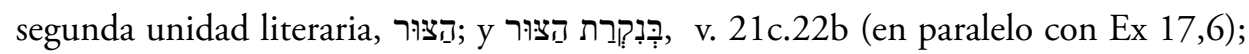
el nombre masculino מָזָז (v. 21b), que da la idea de un lugar, sitio o localidad, se determina por la partícula de complemento con sufijo אִ̣, que traduce "conmigo o junto a mí, lo que hace comprender que ese lugar junto a Dios es el monte Sinaí/ Horeb. El término montaña de Dios o montaña expresan el mismo concepto (Ex 4,27; 18,3; 24,13) e indican que se localiza en el desierto; por tanto, se puede ver la tarea redaccional en los nombres propios (Ex 3,1; 1R 19,8).

Ex 33,12-23 se presenta como el punto de desenvolvimiento de la crisis de infidelidad del pueblo de Israel al incumplir el mandamiento de no adorar otros dioses diferentes a Yahveh (Ex 20,2-6; Dt 5,6,10) ya que, gracias a la mediación de Moisés, él accede a perdonar al pueblo y caminar con él guiándolo por el desierto, hasta el lugar prometido a los padres (Gn 35,12; 15, 18-21; Ex 3,8.15; Nm 14,23; Dt 34,4). La promesa se cumple y se muestra el rostro de Dios, rostro de misericordia y fidelidad, a pesar de la infidelidad del pueblo (Ex 34,6-7).

En el centro de la perícopa, como núcleo del Pentateuco, se plantea la decisión de Dios de caminar con Israel, y se desarrolla el tema de la presencia divina en medio de su pueblo luego de la falta, quien se pregunta si los acompañaría ${ }^{18}$.

En el contexto de la perícopa del Sinaí, Ex 33,12-23 está en el punto de solución del pecado del becerro de oro, donde se rompe la alianza, y la aceptación de Yahveh de perdonar al pueblo su pecado y disponer su renovación, al elaborar las nuevas tablas del testimonio y la promulgación de nuevas leyes.

Así, los análisis realizados permiten diferenciar dos líneas teológicas que recorren todo el Pentateuco y son base de reinterpretación en los demás bloques de la TaNaK: las teologías de la Ley y el culto, que serán profundizadas en el siguiente capítulo,

\footnotetext{
${ }^{17}$ Brien, "Sinaí, Horeb: où est la 'montagne de Dieu'?", 30.

${ }^{18}$ Sanz Giménez-Rico, Cercanía del Dios distante. Imagen de Dios en el libro del Éxodo, 380.
} 
con el apoyo de los resultados de las redacciones deuteronomista y sacerdotal en continuidad exegética y teológica.

\section{Teologías de la Ley y el culto en Ex 33,12-23}

Se parte de las diferentes perspectivas de la teología bíblica en la historia de su configuración, resaltando aportes de autores y modelos como el histórico-descriptivo ${ }^{19}$ o el canónico ${ }^{20}$ (con sus líneas convergentes o divergentes, hasta las nuevas perspectivas del pluralismo teológico presente en el Pentateuco y a lo largo de la Sagrada Escritura). La crítica redaccional permite inducir las teologías emergentes en las unidades literarias, como la del becerro de oro, donde se contienen entre otras las teologías de la Ley y el culto.

La metodología propuesta para el desarrollo teológico de la perícopa, desde la perspectiva del pluralismo teológico, se apoya en los resultados de la crítica literaria y asume el modelo histórico descriptivo. Primero se identifican los textos paralelos a Ex 33,12-23; y luego se relacionan, para establecer el hilo conductor de las teologías específicas de la Ley y el culto, y posteriormente definir los resultados de la relación de los textos seleccionados, así como el significado y aplicación del hilo teológico conductor.

Los criterios que se asumen son: la historia como memoria, la tradición como canal de conservación de dicha memoria y la actualización como proceso de relectura para nuevos contextos de vida.

En relación con la teología de la Ley contenida en la perícopa de Ex 33,12-23, se parte de la aproximación a la noción de Ley en el contexto de la perícopa del Sinaí, que sobrepasa el conjunto de nomos y asume características dinámicas a la par de la configuración de la identidad del pueblo de Israel en su camino por el desierto.

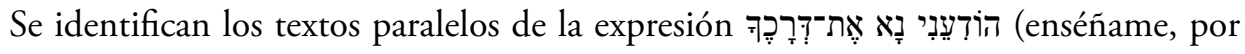
favor, tus caminos), Ex 33,13, con sus acentos deuteronomistas (como se ve en textos afines: Gn 24,40; Dt 8,2.6; Jos 1,8; Jr 2,36; 4,18; 22,21; Sal 27,11; 86,11; 67,3; 119); y desde la relación teológica se establece una analogía entre Ley y caminos en el marco de la alianza, donde se resalta el papel de Moisés como quien escucha la voz de Yahveh y la transmite a su pueblo. Los significados son los siguientes: Torá como caminos de Yahveh y los caminos del hombre guiados por la Ley.

En lo referente a la teología del culto, en la perícopa se reconoce la cuna redaccional sacerdotal y sus aportes a las redacciones finales de la perícopa del Sinaí y el

\footnotetext{
${ }^{19}$ Liverani, Más allá de la Biblia. Historia antigua de Israel; Ferrada Moreira, "Teología e historia en el Antiguo Testamento", 369-389.

${ }^{20}$ Ver a Childs, Teología biblica del Antiguo y del Nuevo Testamento.
} 
conjunto del Pentateuco, pero enfatizando en los aspectos de santidad/consagración, elección y separación del pueblo. En la situación de restauración posexílica, el culto llegó a adquirir una función identitaria y de configuración de la nueva comunidad judía, junto a la Ley ya configurada desde épocas monárquicas y con las reflexiones sobre la desgracia y la esperanza del pueblo.

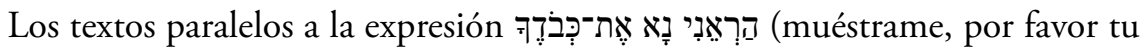

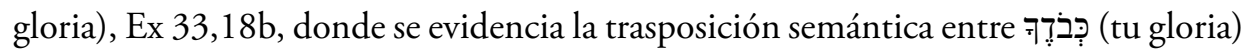
y

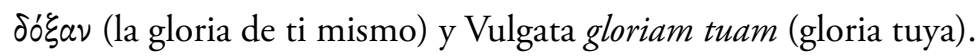

El uso resalta: ver el rostro de otro como señal de aceptación (Gn 33,10); volver el rostro a Dios como señal de arrepentimiento (Job 1,11; 2,5); percibir la luz del rostro de Yahveh (Sal 4,7), contenida en la אהֶל מוֹעֵָד (Ex 29,43-44; 40,34), y el monte Sinaí; el rostro escondido de Yahveh (Sal 13,2; 44,25), unido a su imposibilidad de verlo, como desarrolla la segunda unidad de la perícopa (Ex 33,20.23c y par. Sal 69,18; 102,3; 143,7); el rostro de Dios como promesa (Sal 16,11); el deseo de contemplación; y volver el rostro de Dios como señal de denuncia profética (Ez 6,2;13,17; 21,7;25,2;28,21;29,2; 35,2; 38,2).

La relación teológica muestra la clave de la presencia/ausencia de Yahveh y la posición "ventajosa" de Moisés; el péndulo temático oscila entre la experiencia de vida y de muerte, de dominio y obediencia, de bendición y castigo, de salvación y denuncia. Los escenarios de encuentro son: la tienda, la montaña, un lugar y la roca, plenos de significado cultual y de su perfeccionamiento, de lo transitorio a la estabilidad del Templo. Así, los significados que se obtienen son: rostro de Dios como fuente de bendición y vitalidad; rostro de Dios como causa de muerte; y rostro de Dios como función litúrgica.

El lenguaje empleado en la perícopa indica confidencia y petición, y expresa un ambiente de revelación y de plegaria propios del contexto de la alianza con trasfondo litúrgico. A nivel narrativo se ubica en un escenario cultual, como es la montaña del Sinaí, escenario natural teofánico, y específicamente en la tienda del encuentro, lugar instituido para el encuentro con Yahveh.

Este "estar con" de Yahveh es un requisito absoluto de vida en el pleno sentido del término ${ }^{21}$. Al obtener como resultado la restauración de la alianza quebrantada, esta se asegura con nuevos términos, comprendidos en este estudio como el conocimiento de la Torá-camino y la visión de la gloria-rostro de Yahveh mediante el culto oficial (Ex 34,13-27).

\footnotetext{
${ }^{21}$ Houtman, Historical Commentary of the Old Testament. III. Exodus, 700.
} 
Dichos contrastes teológicos evidencian la reflexión sobre la catástrofe nacional y plantean la necesidad de reconocer el pecado del pueblo y a la vez la urgencia de afianzarse con esperanza a una nueva identidad, cimentada sobre bases primordiales, sólidas y durables. Serán las actitudes de caridad, justicia, acogida y apertura, los nuevos indicadores que permitirán ver la gloria de Yahveh, como lo expresa con un alto grado poético Is 58,7-10.

\section{Actualización de los contenidos de Ex 33,12-23 en las tradiciones interpretativas: halakita y haggadita}

Este apartado presenta una vía de interpretación de Ex 33,12-23 en el contexto del Pentateuco, apoyándose en los resultados de la crítica redaccional y los modelos de teología bíblica de la Ley y el culto ya desarrollados. Esta fase de interpretación y actualización se apoya en los procedimientos propios de la exégesis rabínica, sustentando la posibilidad del midrás en sus vertientes halakita y haggadita.

La perspectiva desde la cual se abordan las tradiciones es la de considerar la exégesis rabínica no solo como un esfuerzo de actualización de los textos y sus contenidos, sino como elaboración propiamente teológica; de ahí que se emplee el termino de teología rabínica, como postula Neusner ${ }^{22}$. Así se proporciona un aporte de continuidad desde los aspectos textuales e históricos hacia la comprensión teológica de los contenidos, que a la vez proporcione elementos para su interpretación y actualización.

Como punto de partida se reconoce la presencia del midrás al interior de la Biblia, el cual se comprende a partir de la constante revisión en el texto y su contexto teológico, actualizando su mensaje a los nuevos contextos de vida y fe de la comunidad creyente. En el sentido estricto de la técnica o las colecciones, al revisar los midrásim rabínicos en lo concerniente a Ex 33,12-23 se verifica que en las épocas de desarrollo del midrás posbíblico no se evidencian aportes sobre esta perícopa, aunque en el contexto se reconocen pistas de comprensión y actualización de sus contenidos, siguiendo la aplicación de las reglas de interpretación propias de la tradición rabínica (atribuida a Hillel, Ismael, Aquiba, junto con la síntesis de José el Galileo ${ }^{23}$. De este modo, por cada unidad literaria del texto con sus respectivas líneas teológicas de la Ley y el culto, se posibilita una perspectiva de actualización de los contenidos redaccionales y teológicos presentes en la perícopa.

\footnotetext{
${ }^{22}$ Ver a Neusner, The Theology of the Oral Torah.

${ }^{23}$ Manns, Le Midrash, approche et commentaire de l'Ecriture, 97.
} 
El midrás rabínico asumió dos orientaciones fundamentales no contrapuestas sino integradas en una visión completiva de la lectura bíblica de carácter actualizador: el midrás halaká y el midrás haggadá. El primero, de dirección moral/legal, y el segundo, de tipo expositivo/didáctico, con intentos parenéticos edificantes ${ }^{24}$ que se refiere al material rabínico no legal, mientras el primero $s^{25}$. Los principios o reglas exegéticas para la interpretación de los textos bíblicos se denominaron middot (medidas).

En relación con la idea del midrás bíblico, "no es exagerado decir que el midrás comienza en el Antiguo Testamento a partir del momento en el cual fueron reunidas tradiciones de origen diferente" ${ }^{26}$, explicación que proporciona la crítica redaccional. Así, estas tradiciones contenían variantes o contradicciones que hoy se ven como fuentes diferentes, mientras que los últimos autores bíblicos buscaron conciliarlas ${ }^{27}$.

Esta apreciación sirve de apoyo para los estudios recientes sobre la LXX, en los que se puede evidenciar que los manuscritos de versiones antiguas reflejan un texto divergente en relación con el Texto Masóretico, TM, mientras que las ediciones finales buscaron acercarlos ${ }^{28}$. Las relecturas en contextos y situaciones de tensión ponen en evidencia esas perspectivas del texto sagrado y la necesidad de la comunidad de ampliar sus perspectivas.

Entre los comentarios midrásicos al Pentateuco propios de las escuelas de los rabinos $^{29}$ cabe indicar que no hay un midrás o una aplicación de middot a Ex 33,1223 aunque, debido a la presencia de pasajes similares que narran el diálogo de Moisés con Yahveh, se podrían aplicar los mismos procedimientos, teniendo en cuenta algunas de las siguientes reglas: las de Hillel (Qal wahomer [ligero y pesado]; Gezerah shawah [lugares paralelos]; Bynyan 'ab [obtención de un principio]; Davar ha-lamed men-inyano [atención al contexto]; Tartey misma' [la búsqueda de un segundo sentido]) y otros como 'al tiqra (diferente vocalización); notaricón (división diversa de una palabra) y la atención a las conjunciones y partículas ${ }^{30}$.

\footnotetext{
${ }^{24}$ Aletti; Gilbert; Ska; y Vulpillières. Vocabulaire raisonné de léxégèse biblique, 106.

${ }^{25}$ Neudecker, The Voice of God on Mount Sinai. Rabbinic Commentaries on Exodus 20:1 in the Light of Sufi and Zen-Buddhist Texts, 23.

${ }^{26}$ Manns, Le Midrash, approche et commentaire de l'Ecriture, 19.

${ }^{27}$ Ibíd.

${ }^{28}$ Law, Cuando Dios habló en griego. La Septuaginta y la formación de la Biblia Cristiana, 35.

${ }^{29}$ Ver a Mekilta de Rabbi, Comentario rabinico al libro del Éxodo.

${ }^{30}$ Muñoz León, "Principios básicos de la exégesis rabínica”, 117-122.
} 


\section{Una teología del Pentateuco como experiencia y praxis del encuentro con Dios}

$\mathrm{Al}$ retomar los desarrollos anteriores se evidencia la riqueza y diversidad de estudios en los aportes actuales sobre el Pentateuco, con la nota de transitoriedad y de apertura a nuevos resultados. Las conclusiones giran en torno de unos ejes orientadores de la articulación entre exégesis, teología y tradición interpretativa desde Ex 33,12-23 para el conjunto del Pentateuco.

\section{Relectura de los textos fundacionales}

Los resultados de la crítica redaccional muestran la heterogeneidad de las fuentes y tradiciones que aportaron a la composición de la perícopa, de la sección del becerro de oro y de la unidad del Sinaí. Esto es indicio del respeto, apropiación y valoración por parte de los redactores de sus tradiciones antiguas. Esta apropiación diseña y remarca elementos que se asumieron como esenciales en la identidad religiosa y cultural del pueblo de Israel. Se consolida la figura de Moisés como mediador, profeta y legislador, y como figura institucional del sacerdocio.

Dicha mediación deja al descubierto la inclinación original del pueblo al pecado, ya configurada en las narraciones del Génesis, pero acentuadas en el pasaje del becerro de oro; en Ex 33,12-23 se resuelve la función de Moisés y se definen los recursos para superar la ruptura entre el pueblo y Yahveh; estos son la Ley, considerada como camino, y el culto, definido en términos de instalación de un lugar santo, expresado con lenguaje epifánico y confidencial.

Los textos fundacionales aportan la primera perspectiva de la Ley e incorporan en época posexílica la urgente definición del culto como garante de la identidad de la nueva comunidad judía.

\section{Imposibilidad de la visión de Yahveh}

Las teologías de la Ley y el culto se presentan en el conjunto del Pentateuco como experiencias de visibilidad/invisibilidad de Yahveh ${ }^{31}$. Los influjos elohistas -con los posteriores desarrollos sacerdotales- enfatizan la distancia entre Dios y el hombre, debido ante todo a la dureza del segundo, a pesar de la fidelidad de Yahveh, como indican las teologías deuteronomistas.

${ }^{31}$ Fornara, La visione contradetta. La dialettica fra visibilità e non-visibilità divina nella Bibbia ebraica, 409. 
Los rasgos de esta distancia se plasman de manera dramática en la perícopa del becerro de oro (Ex 32-34), donde el pecado de idolatría, repetitivo y constante en el pueblo, ocasionó la más profunda ruptura entre este y Yahveh, hasta no considerarlo pueblo suyo y expresar su deseo de exterminarlo, para hacer otro nuevo a partir de Moisés (Ex 32,9-10). Como signos de la ruptura y distancia se consignan: la desinstalación de la tienda del encuentro del centro del pueblo, para ser ubicada por Moisés "a cierta distancia, fuera del campamento" (Ex 33,7), y la afirmación del mismo Yahveh a Moisés de la imposibilidad de ver su rostro (Ex 33,20.23).

La aparente insalvable distancia entre Yahveh y el pueblo hará necesaria la acentuación de nuevas mediaciones, o por lo menos su reforzamiento, como la Ley y el culto, garantía de la presencia de Yahveh en medio de su pueblo. Solo una nueva alianza, o la renovación de la quebrantada por el pecado actuado será la garantía del caminar de Yahveh con su pueblo.

\section{Posibilidad del encuentro con Yahveh}

La tensión presentada a lo largo de los textos del Pentateuco se plantea en términos de visibilidad-invisibilidad de Yahveh. Hay una permanente constatación de la obstinación del pueblo de Israel a no seguir los preceptos de Yahveh (Ex 33,5), con su consecuente distanciamiento, así como la ruptura de las tablas de la Ley y el envío de un mensajero como guía. Incluso con estas situaciones, la tendencia teológica -tanto deuteronomista como sacerdotal- es a la solución de la ruptura y a la presentación de observaciones fundamentales y a la vez prácticas que superen la distancia.

La invisibilidad de Yahveh se dramatiza como la ruptura de la alianza y su expreso deseo de no caminar más con el pueblo (Ex 33,3), enviando un mensajero (Ex 23,20-23; 32,34); pero surge la figura de Moisés como mediador, intercediendo continuamente por el pueblo luego de su pecado.

El momento cumbre del papel intercesor de Moisés se encuentra en Ex 33,12-23, donde él pretende asegurar, en primer lugar, la guía y compañía por parte del mismo Yahveh, lo cual logra en términos de predilección y conocimiento. Así, el pueblo asegura su orientación hacia la tierra prometida en medio del desierto. En este contexto se presenta la Ley como camino, guía y protección.

El pueblo comprenderá que la manera de orientarse es mediante la observancia de los preceptos de Yahveh, promulgados en el Sinaí; por tal razón será preciso renovar la alianza recibiendo unas nuevas tablas de la Ley $($ Ex 34,1-4) y una nueva manifestación 
teofánica de Yahveh (Ex 34,5-9), donde se revelarán los denominados "atributos" de bondad y misericordia, amor y fidelidad, definidos como la autorrevelación de Dios ${ }^{32}$. Yahveh es ante todo el Dios del amor y la fidelidad, quien se manifiesta cercano y atento a su pueblo, aun conociendo su debilidad.

Ante la imposibilidad física y tangible de "ver" a Dios, él mismo propone ser contemplado mediante el culto oficial, inaugurado en el desierto con la tienda del encuentro, diseñado con órdenes precisas de elaboración de los elementos cultuales (Ex 25-30) y con las disposiciones rituales y sacrificiales (Lv). De esta manera se configuran los pilares de la fe y la identidad del pueblo de Israel, con las notas características de la santidad. El pueblo que conserva su esperanza en Yahveh vislumbra el nuevo éxodo como nuevo comienzo, corregido y estable. Ley y culto son dos aspectos de una misma realidad: la de la presencia de Yahveh como Señor y creador, como el Dios de las promesas, siempre dispuesto a escuchar a su pueblo, con la mediación de Moisés, su siervo, reconocido como profeta, legislador y sacerdote.

\section{Fidelidad con apertura histórica}

Las tradiciones interpretativas del judaísmo apropiando las técnicas del midrás indican el sentido solemne y sagrado de la Torá en su unidad ${ }^{33}$, al insistir en la fidelidad de la Palabra de Dios, e interpretarla con fidelidad y respeto, pero adaptándola a las diversas circunstancias de las comunidades, en una continua relectura de la voz de Yahveh (Sal 78,6b-6). En esta tarea continua de actualización con fidelidad al espíritu originario de las Escrituras, las circunstancias históricas son las "voces" divinas que invitan a permanecer en actitud de escucha y respuesta a la Palabra siempre novedosa de Yahveh.

La Ley, vista desde la perspectiva halakita, es norma viva e inspiradora del comportamiento ético, individual y colectivo, y la práctica humana de solidaridad y apertura; implica nuevas dimensiones celebrativas litúrgicas, donde el encuentro con Yahveh se revitaliza con el encuentro comunitario en el templo como su símbolo ${ }^{34}$. La aplicación homilética e interpretativa de la haggadá motiva la experiencia diaria de la fe, como experiencia narrada, transmitida de generación a generación (Sal 78), que reconoce las acciones divinas y las intuiciones de los rabinos, los maestros y guías del pueblo. Estas perspectivas son soporte de la inspiración divina de las Escrituras y de su valor perenne para la comunidad.

\footnotetext{
${ }^{32}$ Sanz Giménez-Rico, Cercania del Dios distante. Imagen de Dios en el libro del Éxodo, 379.

${ }^{33}$ Manns, Le Midrash, approche et commentaire de l'Ecriture, 14.

${ }^{34}$ Vermeylen, El Dios de la promesa y el Dios de la alianza, 285.
} 


\section{Unidad interpretativa}

A nivel de planteamiento y procedimiento, en la investigación se evidencia el aporte integrador de la exégesis, la teología y la tradición interpretativa para la mayor comprensión y apropiación de los contenidos bíblicos. Ante la pregunta de qué enseñar de la Biblia hoy a las comunidades y cómo enseñarlo, esta propuesta integradora puede ser un camino de mayor alcance y mejores resultados. Las tendencias exegéticas buscan afirmar una u otra metodología, así como los diversos y novedosos acercamientos.

Sin embargo, se hace importante articular diacronía con sincronía, partiendo de los textos y conjuntos de libros sagrados y los dos testamentos en unidad, para adentrarse en las teologías presentes como expresión de la fe, la espiritualidad, la experiencia histórica de Yahveh en medio de su pueblo y los esfuerzos por comprender el testimonio de la Escritura. Así, el esfuerzo por aclarar los procedimientos literarios, contextuales y religiosos presentes en Ex 33,12-23 se sumergen en la amplia comprensión de la formulación de la Ley y el culto fundamentados en la perícopa del Sinaí.

Estas amplias unidades se reconocen como el centro del Pentateuco y le dan una dinámica teológica propia, consignada desde los materiales más antiguos hasta sus revisiones y apropiaciones en las redacciones finales, las cuales abren el horizonte comprensivo a los lectores actuales, tanto judíos como cristianos, quienes ven en el Nuevo Testamento la posibilidad de conocer los caminos de Yahveh y ver su rostro en su Hijo Jesucristo, Palabra del Padre, nueva Ley que une a la humanidad y en quien se inaugura el nuevo culto universal.

\section{Conclusiones}

Los resultados del análisis exegético de la perícopa del Ex 33,12-23 permiten comprender una dinámica pedagógica de la nueva alianza entre Dios y el pueblo. La acción comunicativa entre Dios y el hombre-pueblo parte del deseo de Dios de dar una identidad como nueva comunidad mediante una nueva alianza, una nueva forma de comunicación.

Por ello, Dios consolida a Moisés como el mediador entre él y su pueblo, para hacerse visible y caminar con ellos, ofrece al pueblo la Ley como propuesta de camino por el cual lo guía y lo protege y como una norma ética individual y colectiva; y el culto como la forma plena de comunicación y de encuentro con Yahveh y entre la comunidad como expresión de la nueva identidad. Es un Dios amoroso, fiel y cercano que busca la realización personal y comunitaria del pueblo, lo cual genera una nueva forma de relación y de encuentro expresada con categorías comunitarias. 


\section{Referencias}

Aletti, Jean-Noël; Maurice Gilbert; Jean-Louis Ska; y Sylvie Vulpillières. Vocabulaire raisonné de léxégèse biblique. Paris: Du Cerf, 2005.

Bauks, Michaela y Christophe Nihan. Manuel d'exégèse de l'Ancien Testament. Genève: Labor et Fides, 2008.

Blum, Erhard. Studien zur Komposition des Pentateuch. Berlin: De Gruyter, 1990.

Brien, Jacques. "Sinaí, Horeb: où esta la 'montagne de Dieu'?" Le Monde de la Bible 82 (1993): 30-31.

Buss, Martin J. "Bundestheologie im Alten Testament by Lothar Perlitt" [recension]. Journal of Biblical Literature 90/2 (1971): 210-212. Disponible en: https:// doi.org/10.2307/3263763

Childs, Brevard. Teología biblica del Antiguo y del Nuevo Testamento. Salamanca: Sígueme, 2010.

Cortese, Enzo. "Pentateuco: la strada nuova e la vecchia". Liber Annus 43 (1993): 71-87.

Costa, José. La Bible racontée par le Midrash. Paris: Bayard, 2004.

Elliger, Karl, y Rudolph, Wilhelm (eds.). Biblia Hebraica Stuttgartensia. Stuttgart: Deutsche Bibelgesellschaft, 1997.

Emerton, John A. Studies in the Pentateuch. Leiden: Brill, 1990.

Ferrada Moreira, Andrés. "Teología e historia en el Antiguo Testamento". Teología y vida 52/3 (2011): 369-389.

Fornara, Roberto. La visione contradetta. La dialettica fra visibilità e non-visibilità divina nella bibbia ebraica. Roma: Pontificia Universitá Gregoriana, 2004.

García López, Félix. La Torá. Escritos sobre el Pentateuco. Estella (Navarra): Verbo Divino, 2012.

Houtman, Cornelis. Historical Commentary of the Old Testament. III. Exodus. Leuven: Peeters, 2000.

Law, Timothy. Cuando Dios habló en griego. La Septuaginta y la formación de la Biblia Cristiana. Salamanca: Sígueme, 2014.

Liverani, Mario. Más allá de la Biblia. Historia antigua de Israel. Barcelona: Crítica, 2005.

Manns, Frédéric. Le Midrash, approche et commentaire de l'Ecriture. Jerusalem: Franciscan Printing Press, 2001. 
Mekilta de Rabbí, Ismael. Comentario rabinico al libro del Éxodo. Estella (Navarra): Verbo Divino, 1995.

Muñoz León, Domingo. "Principios básicos de la exégesis rabínica”. Revista bíblica 60/2 (1998): 117-122.

Neudecker, Reinhard. The Voice of God on Mount Sinai. Rabbinic Commentaries on Exodus 20:1 in the Light of Sufi and Zen-Buddhist Texts. Roma: Gregorian \& Biblical Press, 2012.

Neusner, Jacaob. The Theology of the Oral Torah. Québec: McGill-Queen's University Press, 1999.

Rendtorff, Rolf. "Das überlieferungsgeschichtliche. Problem des Pentateuch". Zeitschrift für die alttestamentliche Wissenschaft / Beihefte 147 (1977).

Römer, Thomas. La llamada historia deuteronomista. Una introducción sociológica, histórica y literaria. Bogotá: San Pablo, 2014.

Römer, Thomas; Jean-Daniel Macchi; y Christophe Nihan (eds.). Introduction à L'Ancien Testament. Genève: Labor et Fides, 2004.

Rose, Martin. Deuteronomist und Jawist. Untersuchungen zu den Berührungspunkten beider Literaturwerke. Zurich: Theologischer Verlag, 1981.

Sanz Giménez-Rico, Enrique. Cercanía del Dios distante. Imagen de Dios en el libro del Éxodo. Madrid: Universidad Pontificia Comillas, 2002.

Schmid, Hans Heinrich. Der Sogenannte Jawist: Beobachtungen und Fragen zur Pentateuchforschung. Zurich: Theologischer Verlag, 1976.

Ska, Jean-Louis. El Pentateuco: un filón inagotable. Problemas de composición y de interpretación. Aspectos literarios y teológicos. Estella (Navarra): Verbo Divino, 2015. - Introduction à la lecture du Pentateuque. Clés pour linterprétation des cinq premiers livres de la Bible. Bruxelles: Lessius, 2000.

Van Seters, John. "Abraham in History and Tradition". En The So-called Deuteronomistic Redaction of the Pentateuch, editado por John A. Emerton, 58-77. Leuven: International Organization for the Study of the Old Testament, 1989.

Vermeylen, Jacques. El Dios de la promesa y el Dios de la alianza. Santander: Sal Terrae, 1990.

. "L'affaire du veau d'or (Ex 32-34). Une clé pour la 'question deuteronomiste'?" ZAW 97 (1985): 1-23. 